\title{
Detection of HIV genome in HIV antibody negative
} \section{men}

\author{
M PEZZELLA, * F CAPRILLI, $\ddagger$ N VONESCH,$*$ P CORDIALI-FEI, $\ddagger$ G GENTILI $\ddagger$ \\ E STURCHIO,* E MANNELLA $\dagger$ \\ From the Institute of Infectious Diseases, University of Rome "La Sapienza", "National Centre for Blood \\ Transfusions, CRI, Rome, †Dermosyphilopatic Institute S Maria and S Gallicano, $\ddagger$ Rome, Italy
}

SUMMARY The presence of the human immunodeficiency virus (HIV) genome was investigated by applying in situ hybridisation techniques to peripheral blood mononuclear cells (PBMCs). Twenty asymptomatic anti-HIV seronegative homosexual men were the subjects of our study. The cells were hybridised with: (1) an SP 64 plasmid containing the nine-kilobase SstI-SstI viral insert from the lambda BH 10 recombinant clone; this can recognise both viral RNA and proviral DNA, and (2) with a pA01 plasmid containing HBV DNA genome. The DNA probes were modified by inserting an antigenic sulfone group in the cytosine moieties and the visualisation was performed by a double antibody immunohistochemical reaction. In two subjects both the HIV genome and HBV DNA were detected whereas another two subjects were positive for HBV DNA and for the HIV genome respectively. Thus people who are seronegative for anti-HIV specific antibodies may be infected with HIV.

HIV infection is transmitted by whole infected blood or blood products and by both homosexual and heterosexual intercourse. Heterosexual transmission, both female to male and male to female, is not uniformly distributed in Europe and Africa. Among homosexual men the spread of the virus is well documented and associated both with the number of sexual partners and the practice of receptive or insertive anal intercourses. ${ }^{12}$ Several epidemiological and clinical observations support the existence of long latency, recently estimated to be in the range of four years before seroconversion, ${ }^{34}$ characterised by low or absent viral expression and absence of detectable specific antibodies. During this long period of time the infected subjects may represent a potential source of transmission because they may continue to donate blood for transfusion and have unprotected sexual intercourse. In this situation the diagnosis based on the detection of anti-HIV antibodies may not identify all the infected persons. ${ }^{5}$ The aim of our investigation was to detect both HBV DNA and HIV genome by in situ hybridisation in peripheral blood mononuclear cells of asymptomatic seronegative homosexual men

Address for reprints: Prof Mario Pezzella, Institute of Infectious Diseases, Policlinico Umberto I University of Rome "La Sapienza" Viale Regine Elena 324 00161, Rome, Italy

Accepted for publication 20 June 1989 as an alternative to virus isolation, antigen-capture assay and detection of core antigen p 24 in serum. HBV DNA was used to investigate the relationship between HIV and HBV expressions at cellular level in patients at risk for AIDS.

\section{Material and methods}

\section{PATIENTS}

Twenty asymptomatic homosexual or bisexual volunteers aged 27-55 years who in the last two years had had unprotected sexual intercourse with several partners were included in our prospective study. All the subjects were selected from a cohort of 368 patients attending the Sexually Transmitted Diseases Clinic of our Public Health Service from January to June 1988. None had used intravenous drugs. Data on sexual activity and past sexually transmitted diseases were available at admission. All the homosexual men were interviewed according to a detailed standardised questionnaire administered by expert interviewers.

SEROLOGICAL ANALYSIS

Hepatitis B virus antigens ( $\mathrm{HBsAg}, \mathrm{HBeAg}$ ) and antibodies (anti-HBs, anti-HBc, anti-HBcIgM and anti-HBe) were evaluated by radioimmunoassay methods (Abbott Laboratories and Sorin Biomedica). The presence of HIV-1 antigen and antibodies to HIV1 were investigated by ELISA (Dupont and ELAVIA 
Ac-Ab-Ak-I); the antibodies to anti-HIV 1 were confirmed by Western Blot (LAV BLOT I Pasteur). Antibodies to CMV and HSV2 were measured by ELISA (ELISA CMV IgG Sclavo and Herpes simplex 2 IgG Ismunit). For identification of Neisseria gonorrhoeae the urethral samples were examined by Gram stain and then cultured on both selective and nonselective media. The confirmation of positivity was performed by identification of oxidase-positive colonies and fermentation tests (Neisseria, Pasteur). Antibodies to Treponema pallidum were estimated by the haemagglutination reaction (TPHA-test Boehzinger). The identification of cardiolipin antigen was performed by microflocculation reaction (Microgen Sclavo).

\section{CELLS}

Peripheral blood mononuclear cells were separated from heparinised blood samples on Ficoll-Hypaque gradients. Most of the cells were removed at the serum-density gradient interface, washed three times in RPMI 1640 and resuspended at a concentration not exceeding $1 \times 10^{5} / \mathrm{ml}$. The total T cell count and T4/ T8 phenotypes were determined by indirect immunofluorescence using OKT3, OKT4, OKT8 and fluorescein isothiocyanate (FITC) $F(a b) 2$ anti-mouse fragment (Ortho) and examined with a UV Nikon apparatus according to our current procedure. Samples of $10^{5}$ cells were cytocentrifuged on to microscope slides, air-dried, fixed in acetone for 5 minutes and then stored at $-20^{\circ} \mathrm{C}$ until used for hybridisation. HIV infected and non infected $\mathrm{H} 9 \mathrm{~T}$ cell culture lines were cytocentrifuged and fixed as described above.

\section{IN SITU HYBRIDISATION}

Three different probes were used for the hybridisation reactions: (a) an sp 64 plasmid containing the ninekilobase SstI-SstI viral insert lambda BH 10 corresponding almost to the entire HIV genome, lacking 180 base pairs of the $5^{\prime}$ long terminal repeat (LTR) sequence; ${ }^{67}$ (b) the whole HBV genome, approximately $3.3 \mathrm{~kb}$ long, purified from plasmid pA01, ${ }^{8}$ (c) the pBR322 plasmid lacking any viral insert. The hybridisation reaction was carried out according to the method previously described. ${ }^{9}$ Briefly the three double stranded heat denaturated DNA probes were labelled by incorporation of an antigenic sulphone group into the cytosine residues (Chemiprobe, Orgenics). All the cytocentrifuged PBMCs were treated at $80^{\circ} \mathrm{C}$ for 5 minutes to inhibit endogenous alkaline phosphatase and then overnight at $37^{\circ} \mathrm{C}$ with $20-30 \mu 1$ of hybridisation solution ( $2 \mathrm{X}$ sodium citrate buffer, $50 \%$ deionised formamide, $10 \%$ dextran sulphate and DNA at a final concentration of $5.59 \mu \mathrm{g} / \mathrm{ml}$ ). The immunological visualisation was performed by a double antibody system using firstly a specific mono- clonal antibody to the sulfone group and then an alkaline-phosphatase conjugated anti-mouse antibody. The nitro blue tetrazolium, used as chromogenic substrate, was converted into an insoluble dye. The precipitates showed the location of the immune reaction and indicated exactly the presence of sulphonated DNA. All the samples were treated with the three DNA probes and with the hybridisation mixture lacking probes.

\section{CONTROLS}

The specificity of the hybridisation reaction was proved by positive and negative controls. The negative controls included: (a) HIV infected H 9 T cell culture hybridised with the HBV DNA probe and with the pBR322 plasmid lacking any viral insert; (b) $\mathrm{H} 9 \mathrm{~T}$ cell culture lines hybridised with all the three probes; (c) peripheral blood mononuclear cells from 20 healthy selected heterosexual men aged $25-40$ years hybridised with all three probes. As positive controls we used: (a) HIV infected $\mathrm{H} 9 \mathrm{~T}$ cell culture lines hybridised with the SP 64 plasmid containing the HIV viral insert; (b) liver sections from $\mathrm{HBsAg} / \mathrm{HBeAg}$ positive patients affected by chronic active hepatitis not at risk for AIDS.

\section{Results}

On serological analysis all the subjects were negative both for anti-HIV antibodies (ELISA confirmed by Western Blot) and serum HIV-1 antigen. Nine of 20 subjects were immune to HBV (anti-HBs, anti-HBc and anti-HBe positive), three were reactive to $\mathrm{HBsAg}$, and $\mathrm{HBeAg}$ and eight were susceptible to $\mathrm{HBV}$ infection. Ten subjects were positive for anti-HSV 2 and 16 for anti-CMV. Evidence of current infection with gonorrhoea and current or past infection with syphilis was present in five and eleven subjects respectively (table). The T4/T8 ratio ranged between 0.75 $2 \cdot 25$ (mean 1.4). The HIV infected H 9 T cell culture hybridised with the SP 64 plasmid containing viral insert lambda BH 10, showed an intracytoplasmic granular staining. In some cases also a nuclear granular staining was observed perhaps suggesting the presence of proviral DNA. The $\mathrm{H} 9$ non infected T cell culture and cells from selected heterosexual blood donors were negative with the three probes. The same negative pattern was observed in the cells from all the subjects when treated with the hybridisation mixture lacking probes or containing pBR322 plasmid lacking viral insert (fig 1). Liver biopsy sections obtained from three patients affected by chronic active hepatitis but not at risk for AIDS, showed intracytoplasmic granular staining only when hybridised with the HBV DNA probe.

Three subjects exhibited a positive reaction after 
Table Correlation between sexually transmitted diseases, presence of antibodies and in situ hybridisation

\begin{tabular}{|c|c|c|c|c|c|c|c|}
\hline \multirow[b]{2}{*}{$N$} & \multicolumn{2}{|c|}{ Sexually transmitted diseases } & \multicolumn{3}{|l|}{ Antibodies } & \multicolumn{2}{|c|}{ in situ hybridisation } \\
\hline & Syphilis & Gonorrhoea & anti-HBc & anti-HSV2 & anti-CMV & $H B V$ & HIV \\
\hline 1 & - & - & - & + & + & - & - \\
\hline 2 & - & - & + & - & - & - & - \\
\hline 3 & + & + & - & + & + & - & - \\
\hline 4 & + & - & + & + & + & + & + \\
\hline 5 & + & - & + & + & + & - & - \\
\hline 6 & - & - & + & + & + & - & - \\
\hline 7 & - & - & - & - & + & - & - \\
\hline 8 & + & + & + & - & + & - & + \\
\hline 9 & + & - & + & - & + & - & - \\
\hline 10 & + & - & + & + & + & - & - \\
\hline 11 & - & - & + & - & + & - & - \\
\hline 12 & - & - & + & - & - & - & - \\
\hline 13 & + & + & + & + & + & + & + \\
\hline 14 & + & - & - & - & + & + & - \\
\hline 15 & + & - & + & - & + & - & - \\
\hline 16 & - & - & - & + & - & - & _ \\
\hline 17 & - & - & + & + & + & - & - \\
\hline 18 & + & - & + & + & - & - & - \\
\hline 19 & - & + & + & - & - & - & - \\
\hline & + & + & + & + & + & - & - \\
\hline Total 20 & 11 & 5 & 17 & 10 & 16 & 3 & 3 \\
\hline
\end{tabular}

Abbreviations: $-=$ negative; $+=$ positive; anti-HBc = antibody to Hepatitis B core; anti-HSV2 = antibody to Herpes simplex 2; anti$\mathrm{CMV}=$ antibody to cytomegalovirus

hybridisation with SP 64 plasmid containing HIV viral insert (table, cases no $4,8,13$ ) and HBV DNA probe (table, cases no 4,13,14). The T4:T8 counts of those with positive reaction for HIV genome were respectively $1.8 ; 1.3 ; 1.4$. The HIV genome sequences were visualised in the cytoplasm of mononuclear cells as a granular staining, thus indicating viral replication, in some cases a nuclear positivity was also observed (figs 2,3 ). In all three cases the number of cells showing hybridisation with HIV ranged between $0 \cdot 1-1 \%$. Moreover the signal intensity was different from cell to cell. In some cells a strong staining reaction was found suggesting the presence of many viral genome copies whereas in others there was only a very low signal

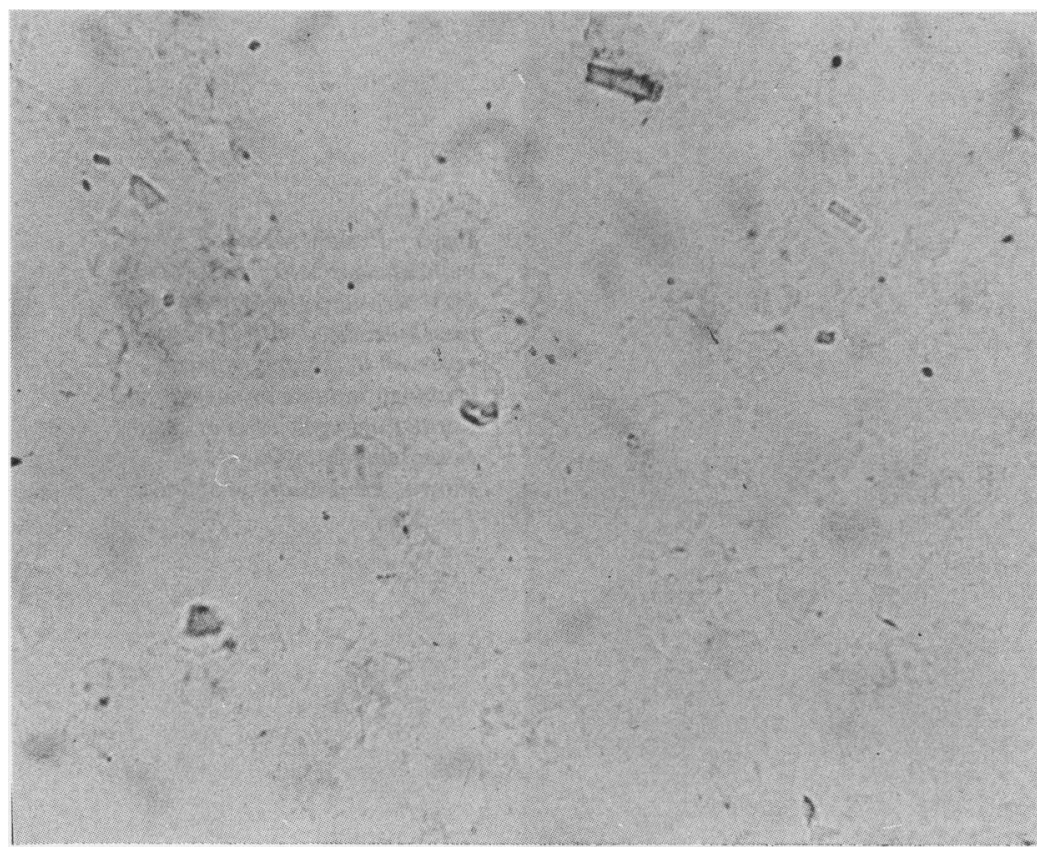

Fig 1 Peripheral blood mononuclear cells from an antiHIV sero-negative homosexual man treated with hybridisation mixture containing pBR322 plasmid lacking viral insert. The same pattern of unstained cells was observed with a hybridisation mixture lacking probes. All cells are unstained. ( $\times 500)$ 


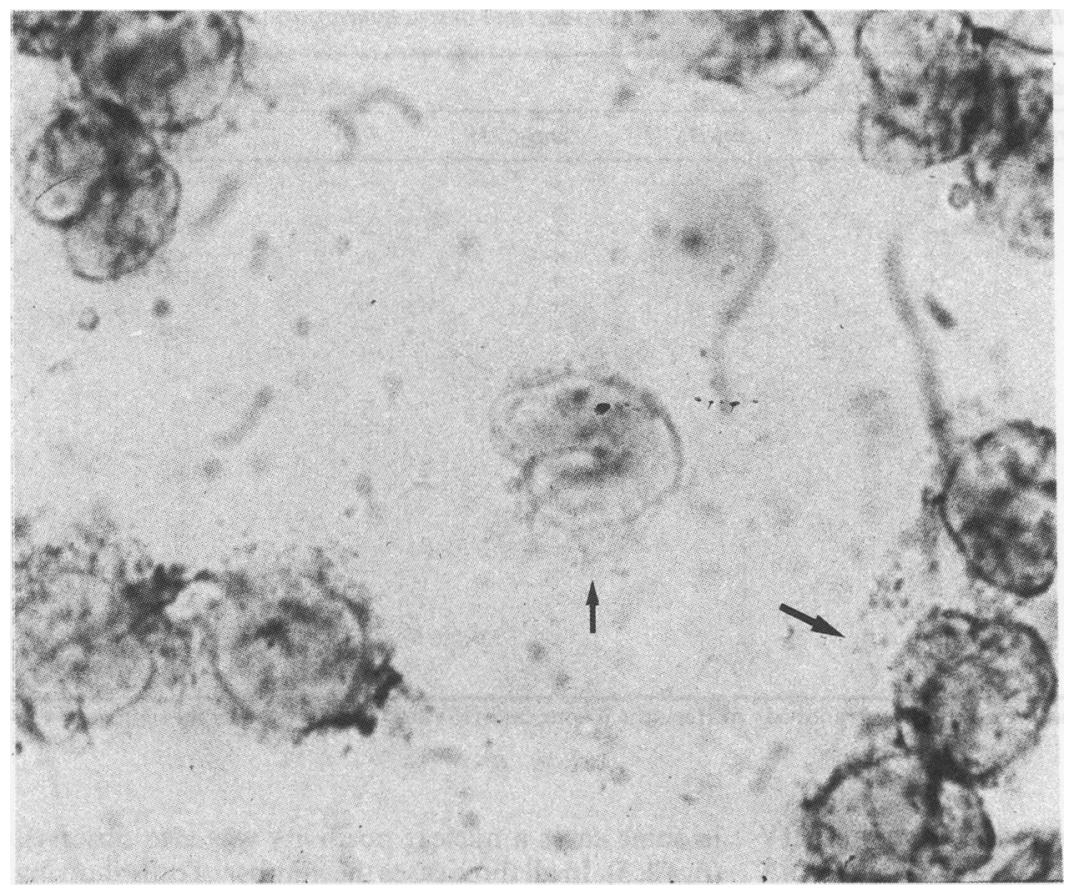

Fig 2 Peripheral blood mononuclear cells from an antiHIV sero-negative homosexual man hybridised with HIV probe (case no 4). A negative cell showing details consistent with that of a monocyte is shown. Positive cells resembling lymphocytes with intracytoplasmic and nuclear granular staining are also demonstrated (arrows). All cells are unstained. $(\times 1000)$

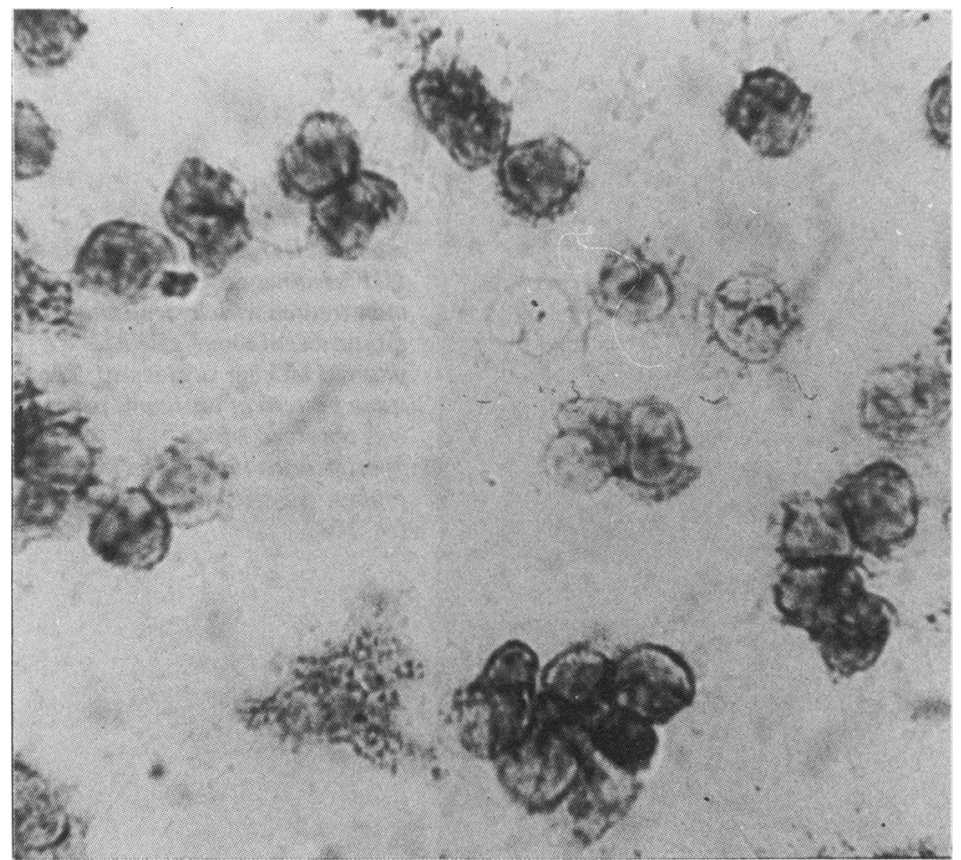

Fig 3 Peripheral blood mononuclear cells from an antiHIV sero-negative homosexual man hybridised with HIV probe (case no 8). A well defined granular staining at nuclear and intracytoplasmic level of cells resembling lymphocytes is shown. All cells are unstained. $(\times 500)$ 


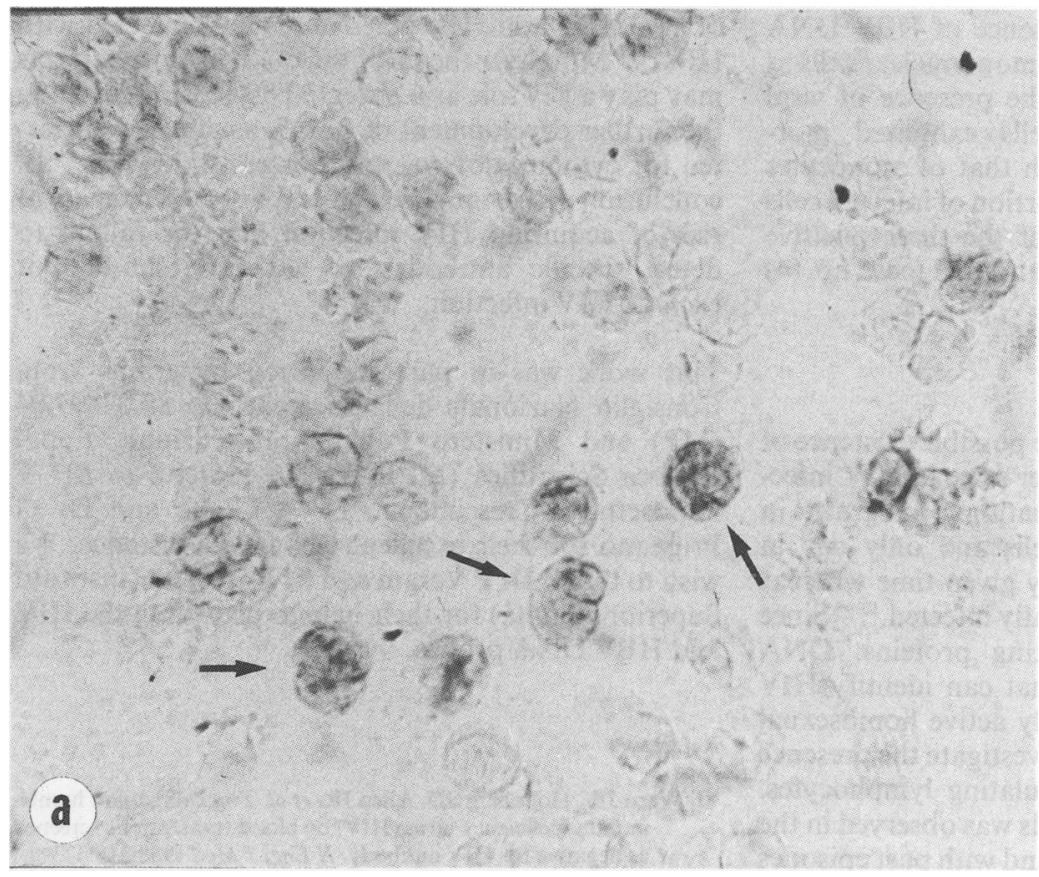

Fig 4 Peripheral blood mononuclear cells from an antiHIV seronegative homosexual man hybridised with $\mathrm{PAOI}$ plasmid containing the whole HBV genome. The stained cells showed morphological details consistent with that of lymphocytes and monocytes (arrows). All cells are unstained $((a) \times 500,(b) \times 1000)$

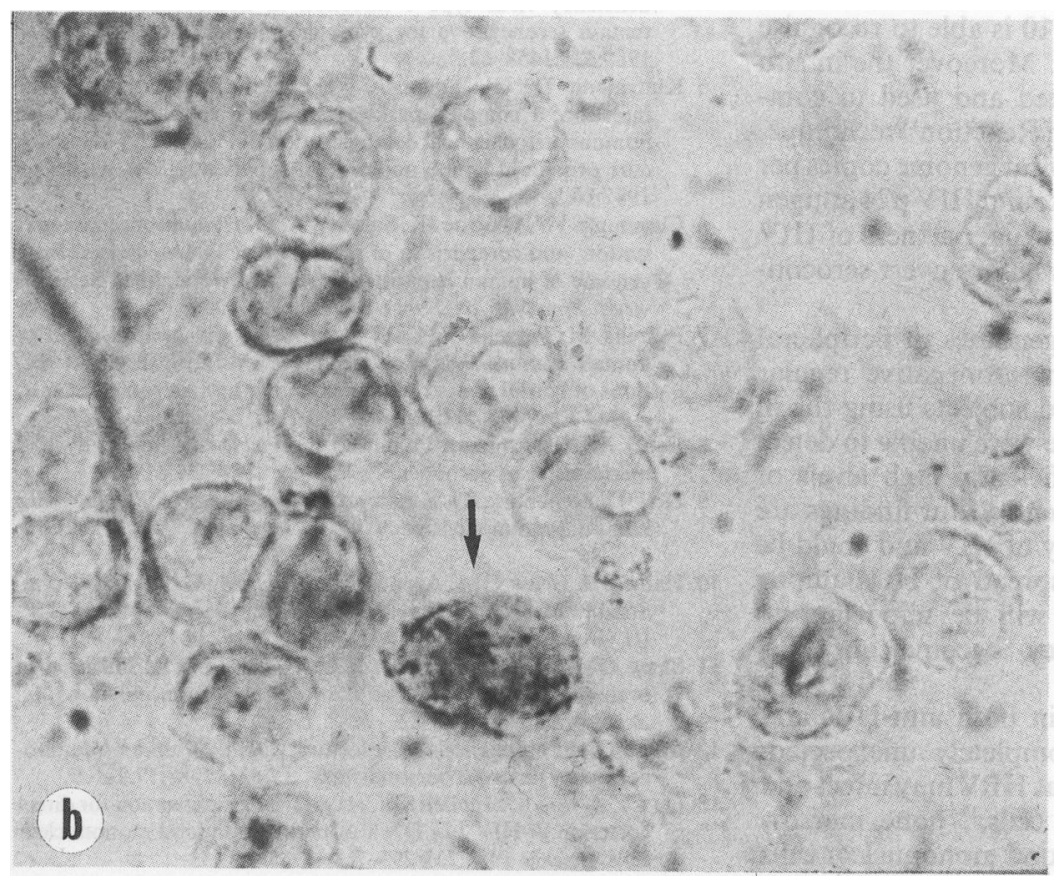


intensity. In three cases the presence of HBV DNA was observed in the cytoplasm of mononuclear cells as a granular staining suggesting the presence of viral replication. Some of these cells exhibited morphological details consistent with that of monocytes (fig 4). In all three cases the proportion of infected cells was less than $0.1 \%$. Two out of the three positive subjects were anti-HBs positive and one (case no 14) was positive only for anti-HBc.

\section{Discussion}

There is a great need to verify the possible existence of a prolonged asymptomatic carrier state in HIV infected subjects. Viral genetic information is integrated in the genome of HIV-infected cells and only one in $10^{4}-10^{5}$ cells express virus at any given time whereas perhaps one in ten might be latently infected. ${ }^{10-12}$ Since the virus is not actively making proteins, DNA detection is the only method that can identify HIV infection. We studied 20 sexually active homosexual men with multiple partners to investigate the presence of latent HIV infection in circulating lymphocytes. The presence of HIV infected cells was observed in the subjects with higher sexual risk and with past episodes of syphilis and gonorrhoea. The in situ hybridisation method is very useful for the detection of latent HIV infection; it gives qualitative information and accurately reflects the distribution of HIV genome within the .cells. The HIV genome sequences were located in the cytoplasm and sometimes in the nucleus because the probe lambda $\mathrm{BH} 10$ is able to recognise both RNA and proviral DNA. Moreover the in situ hybridsation could be correlated and used to complement the "Polymerase Chain Reaction" technique, especially when the number of viral genome copies per cell is very low. ${ }^{13}{ }^{14}$ Ranki et $a l^{15}$ found HIV p24 antigen in sera, from the seronegative sexual partners of HIV seropositive men, 6-14 months before overt seroconversion.

Recently we detected HIV genomes in peripheral blood mononuclear cells from seronegative regular sexual partners of HIV infected subjects using the in situ hybridisation method. ${ }^{16}$ We were unable to detect HIV p24 antigen because sufficiently high levels of antigen are only present transiently. Our findings are consistent with the long latency of HIV and could be relevant to the uncontrolled spread of HIV among homosexual men. Follow-up will be important to check when or whether they become anti-HIV positive.

The finding of HBV DNA in both anti-HBs and anti-HBc subjects was not completely unexpected. Previous studies have shown that HBV may infect and replicate in pancreatic acinar cells, ${ }^{17}$ bone marrow cells, ${ }^{18}$ and also in peripheral blood mononuclear cells of anti-HBs, anti-HBc positive patients infected with HIV ${ }^{1920}$ Moreover the HBV infection in these subjects may play a key role as a potential cofactor facilitating the further development of AIDS, as already suggested for cytomegalovirus and Epstein-Barr virus. ${ }^{21}$ In conclusion active homosexual and bisexual men are at risk of acquiring HIV infection and the failure to detect specific antibodies to anti-HIV should not exclude HIV infection.

This work was in part supported by grants from Consiglio Nazionale delle Ricerche, no 88.03497.04 (MP) and Ministero Pubblica Instruzione, Fondi Ricerca Scientifica (MP). We are grateful to Mr V Panosetti, E Crescimbeni, Dr A Giglio and Dr G Prignano for their excellent technical assistance. We wish to thank Dr P Verani and M Rapicetta (Instituto Superiore Sanità) for their help in providing the HIV and HBV DNA probes.

\section{References}

1 Ward JW, Holmberg SD, Allen JR, et al. Transmission of human immunodeficiency virus (HIV) by blood transfusions screened as negative for HIV antibody. $N$ Engl J Med 1988;318:473-8.

2 Piot P, Plummer FA, Mhalau FS, Lamboray JL, Chin J, Mann JM. AIDS: an international perspective. Science 1988;239: 573-9.

3 Lui KJ, Darrow WW, Rutherford GW. III: a model-based estimate of the mean incubation period for AIDS in homosexual men. Science 1988;240:1333-5.

4 Imagawa DT, Lee MH, Wolinsky SM, et al. Human immunodeficiency virus type 1 infection in homosexual men who remain seronegative for prolonged periods. $N$ Eng $J$ Med 1989;320:1458-62.

5 Klatzmann D, Gluckman JC. The pathophysiology of HIV infection: a complex pathway of host-virus interaction. An immunohistochemical demonstration of P 24 HTLV III major core protein in lymph nodes of LAS patients. Histopathology 1987;10:5-13.

6 Cummings IW, Browne JK, Salser WA, et al. Isolation, characterisation, and comparison of recombinant DNAs derived from genome of human hepatitis B virus and woodchuck hepatitis virus. Proc Nat Acad Sci USA 1980;77:842-6.

7 Pezzella M, Pezzella F, Galli C, et al. In situ hybridisation of human immunodeficiency virus (HTLV-III) in cryostat sections of lymph nodes of lymphadenopathy syndrome patients. J Med Virol 1987;22:135-42.

8 Fauci AS. The human immunodeficiency virus: infectivity and mechanisms of pathogenesis. Science 1988;239:617-22.

9 Ho DD, Pomerantz RJ, Kaplan JC. Pathogenesis of infection with human immunodeficiency virus. $N$ Engl J Med 1987;317: 278-86.

10 Hahn BH, Shaw GM, Arya SK, Popovic M, Gallo RC, WongStaal F. Molecular cloning and characterisation of the HTLVIII virus associated with AIDS. Nature 1984;312:166-9.

11 Shaw GM, Harper M, Hahn BH, et al. HTLV-III infection in brains of children and adults with AIDS encephalopathy. Science 1985;227:177-82.

12 Mims CA. Pathogenesis of infection with the human immunodeficiency virus-a personal view. J Infect 1988;17:221-9.

13 Ou CY, Kwok S, Mitchell SW, et al. DNA amplification for direct detection of HIV-I in DNA of peripheral blood mononuclear cells. Science 1988;239:295-7. 
14 Saiki RK, Gelfand DH, Stoffel S, et al. Primer-directed enzymatic amplification of DNA with a thermostable DNA polymerase. Science 1988;239:487-91.

15 Ranki A, Krohn M, Allain J-P, et al. Long latency precedes overt seroconvertion in sexually transmitted human-immunodeficiency-virus infection. Lancet 1987;ii:589-93.

16 Pezzella M, Mannella E, Mirolo M, et al. HIV genome in peripheral blood mononuclear cells of seronegative regular sexual partners of HIV infected subjects. J Med Virol 1989;28.

17 Shimoda T, Shikata T, Karosawa T, et al. Light microscopic localisation of hepatitis B virus antigens in the human pancrease: possibility of multiplication of hepatitis B virus in the human pancreas. Gastroenterology 1981;81:998-1002.

18 Romet-Lemonne JL, Elfassi E, Haseltine W, Essex M. Infection of bone marrow cells by hepatitis B virus. $J$ Med Virol 1985;17: 73-81.

19 Laure F, Zagury D, Saimot A, Gallo RC, Hahn BH, Brechot C. Hepatitis B virus DNA sequences in lymphoid cells from patients with AIDS and AIDS-related complex. Science 1985;229:561-3.

20 Noonan CA, Yoffe B, Mansell PWA, Melnick JL, Hollonger FB. Extrachromosomal sequences of hepatitis B virus DNA in peripheral blood mononuclear cells of acquired immune deficiency syndrome patients. Proc Nat Acad Sci USA 1986;83:5698-702.

21 Drew WL, Mintz L, Milner RC, et al. Prevalence of cytomegalovirus infection in homosexual men. $J$ Infect Dis 1981;143:188-93. 